cidas, tal vez durante la Francesada, las actuales son obra del escultor Ricardo Font y fueron colocadas en $1948^{10}$.

El gran relieve de San Pedro es obra absolutamente barroca, inspirada en las apoteosis de santos que se multiplican en las iglesias de la ciudad de Roma y nos apuntan a la larga estancia de Francisco Gutiérrez en la Ciudad Eterna y a su aprendizaje con Giovanni Battista Maini de tradición aun berninesca ${ }^{11}$. El escultor pese a sus ideales académicos no pudo sustraerse al efectismo teatral de las grandes composiciones del barroco tan acordes con una manera muy popular de entender y explicar el hecho religioso.

Nada seguro podemos apuntar a cómo llegó esta pieza a la sacristía de la Enfermería de la V.O.T., pero es lógico pensar en una donación muy posiblemente del propio escultor a quien sabemos relacionado en algún momento con la V.O.T. y sobre todo con el desaparecido convento franciscano de San Gil de los barrios madrileños de Afligidos y Leganitos.

Juan Nicolau Castro

Academia de Bellas Artes de Toledo

\title{
UNA OBRA INÉDITA DE 1661 DEL PLATERO FRANCISCO DE SALINAS
}

El estudio de la Platería suscita cada día mayor interés entre los especialistas y los interesados por la Historia del Arte tanto fuera como dentro de nuestras fronteras. Testimonio de ello son tanto las publicaciones referentes como las continuas apariciones de piezas de plata en el comercio internacional de arte.

$\mathrm{Si}$ bien es cierto que son muchas las obras de arte que no habitan hoy en el escenario para el que fueron concebidas, en el caso de las obras de plata los gustos de la época, las modas, el deseo del coleccionista han propiciado el traslado o la fundición haciéndolas en muchos casos susceptibles de pérdida o difícil localización, por lo que la tarea del investigador se hace más ardua. Es por todo ello por lo que en este trabajo queremos dar a conocer una obra que ha llegado a traspasar el umbral de nuestro país pero afortunadamente no de nuestra investigación.

Tras esta pretensión late el deseo de no dejar escapar al conocimiento científico una pieza de carácter inédito, obra de especial interés no solamente por sus características peculiares que la afilian sin duda a la platería de Toledo, sino también por su calidad (Fig. 8).

La pieza es un copón de plata sobredorada con esmaltes opacos de color azul y detalles ambarinos. Mide 46,3 cms. de altura y presenta buen estado de conservación. En el borde vertical del pie puede leerse la inscripción: «DIO ESTE COPON DE LIMOSNA EL LLDO ROQVE DE HRRERA RAC ${ }^{o}$ DE LA SANTA YGLESIA DE TOLEDO ANO DE 1661». En el interior del pie marca: SA/LINS.

La obra ha aparecido en el comercio londinense y en su catalogación se habla de una obra estilo Herrera datable cerca de 1620. Las afirmaciones relativas a material, estado de conservación, medidas, parece que responden a la realidad, pero sin duda, la fecha ofrecida no resulta convincente.

Tampoco la interpretación tanto de la marca como de la inscripción que ostenta la pieza parece la más acertada tal como a continuación expondremos. El copón se clasifica como

${ }^{10}$ Fr. A. Navarro y Fr. A. Muñoz: o.c., p. 34.

11 Francisco Portela: «Francisco Gutiérrez y el sepulcro del Rey Fernando VI», en El Arte en las Cortes Europeas del siglo XVIII, Comunidad de Madrid, 1987, pp. 599-607. 
obra de algún miembro de la familia Salinas aunque a continuación se pone en tela de juicio el hecho de que la obra haya sido realizada por artífice toledano, argumentando que en esta época tal apellido se encuentra también en Sevilla, Madrid y otros lugares.

El copón consta de copa hemiesférica coronada por tapa que se adorna con pequeña cupulilla. El astil es troncocónico de inicio moldurado y contario en la base del cuello. El nudo presenta forma de jarrón con baquetón saliente y lleva un gollete cilíndrico en cuyo extremo se repite el motivo del contario que conduce al pie; circular y con zona intermedia de sección convexa. La decoración de toda la pieza, tanto en la tapa, nudo y pie está constituida por costillas que alternan con espejos ovales esmaltados enmarcados por adorno picado de lustre. El conjunto culmina en figura de la Virgen María y el Niño sobre esfera.

Deteniéndonos en el problema de las marcas, asunto que como se ha advertido provoca disertaciones varias, la primera conclusión es que la marca SA/LINS corresponde al apellido Salinas. En la clasificación a la que aludimos se ha puesto en duda la procedencia de tal apellido del foco toledano, primera interpretación que tenemos que contradecir. Si bien es cierto que este apellido puede encontrarse en otras áreas castellanas y que la obra podría haber sido realizada por un platero foráneo de Toledo, lo que es indudable es que conlleva las características peculiares de la platería toledana para este tipo de pieza de pontifical. Por otro lado, es interesante refrescar las memorias trayendo a colación la destacada importancia del obrador de los Salinas a lo largo de todo el siglo XVII, lo que supone un apremiante más a la hora de atribuir la obra a uno de estos grandes artífices, ya que la pieza no es sino un ejemplar de primera calidad.

Convendrá señalar aquí que conocemos a distintos plateros con tal apellido trabajando en Toledo a lo largo de la centuria. Tanto Ramírez de Arellano ${ }^{1}$ como Parro ${ }^{2}$ Alcolea ${ }^{3}$ y posteriormente otros, han coincidido en presentar a Andrés de Salinas como uno de los principales plateros toledanos de la primera mitad del siglo XVII. Al igual que su padre, Vicente Salinas ocupa el cargo de platero catedralicio y le secunda en su buen quehacer ganando según Arellano la calificación de «artista de primer orden, a la altura de Merino y de Valdivieso» ${ }^{4}$.

Ciertamente tales artífices merecen ocupar un lugar destacado en cualquier historia de la platería toledana e incluso en cualquier platería peninsular, pero si continuamos avanzando en el tiempo nos encontramos con un platero llamado Francisco Andrés de Salinas, quien probablemente debió de aprender del arte de su padre y de su abuelo y de quien no disponemos por el momento de la documentación necesaria para situarle en el lugar que seguramente merece. Tenemos noticias gracias a Pérez Sedano de que Francisco de Salinas realiza en el año 1644 los bronces de la mesa que se encontraba en la sala capitular de verano de la catedral de Toledo y que en 1646 se le paga la obra del águila de bronce que adorna el atril de hierro catedralicio que había comenzado su padre ${ }^{5}$.

Por otro lado, existe constancia de que junto a Andrés de Bejarano es el artífice que labra en 1651 la corona de la Virgen del Sagrario en sustitución de la que en 1556 realizó Carrión y que hoy alberga la Capilla del Tesoro catedralicia ${ }^{6}$. En otra ocasión se cita a nuestro

1 R. Ramírez de Arellano: Catálogo de artífices que trabajaron en Toledo, y cuyos nombres y obras aparecen en los Archivos de sus parroquias, Toledo, 1920, p. 262.

2 S. R. Parro: Toledo en la mano, Toledo, 1857, p. 437.

S. Alcolea: Artes decorativas de la España cristiana (siglos IX-XIX) en Ars Hispaniae, XX, Madrid, 1975, p. 212.

R. Ramírez de Arellano: Estudio sobre la historia de la orfebrería toledana, Toledo, 1915, p. 357.

5 F. Pérez Sedano: Datos documentales inéditos para la historia del arte, I, notas del archivo de la catedral de Toledo, Madrid, 1914, pp. 102-103.

6 M. Revuelta: Inventario Artístico de Toledo, Madrid, 1983, p. 342. 
artífice como autor del frontal de altar realizado junto a Virgilio Fanelli hacia 1688 de la Capilla de la Descensión de la catedral ${ }^{7}$.

Teniendo en cuenta tanto la inscripción que ostenta la pieza en la que se detalla que ésta fue donada por un racionero de la catedral de Toledo en el año 1661 como las características estilísticas y tipológicas que a continuación se analizarán, la obra no puede sino corresponder a la segunda mitad del siglo XVII y no cerca de 1620 como se especificaba en el comentario de la pieza. Restringiéndonos a este espacio temporal sin duda debe tratarse de Francisco Andrés de Salinas ya que en estos momentos tanto su abuelo como su padre ya habían fallecido.

Aparte de otras referencias encontradas en los archivos fruto de nuestra propia investigación que documentan su actividad en el Toledo del momento ${ }^{8}$ estas tres obras citadas anteriormente nos llevan a realizar la siguiente argumentación.

En primer lugar, el hecho de trabajar para la catedral implica sin duda prestigio dentro del área toledana, que puede venir motivado no sólo por su apellido sino por la calidad de sus trabajos, hecho que queda atestiguado en la obra que se presenta.

La siguiente deducción viene conducida por la segunda obra que mencionamos. Se trata de una corona que requiere de la técnica y la sabiduría de un buen artista, sin duda un encargo que no se ofrecería a cualquier platero toledano. Por otro lado, la atribución de la autoría de la pieza a Francisco de Salinas, además de estar motivada por las razones estilísticas y tipológicas a las que se ha aludido, se relaciona con el hecho de que este artífice trabajara con Virgilio Fanelli, un platero ligado a la catedral y que demuestra en sus obras una sobresaliente calidad y una destacada trayectoria profesional en el Toledo de la época.

Debemos advertir que Ramírez de Arellano publicó algunas noticias sobre un Vicente de Salinas, platero toledano documentado desde 1660 y que falleció en 1680. Aunque se desconoce su parentesco con los demás plateros de este apellido sospechamos que fue nieto de Andrés, hijo de Vicente y hermano de Francisco. Podría pensarse que él fuera el artífice del copón que estudiamos pero, sin descartarlo por completo, opinamos que habiendo sido contraste ${ }^{9}$ de la ciudad como documentó Ramírez de Arellano es muy difícil que actuara como artífice. Ninguna noticia le muestra realizando obras de platería a excepción de una recogida por el citado autor que se refiere a una lámpara pagada en 1661 para la capilla fundada por don Alonso Sánchez Hurtado en la iglesia de la Trinidad y que dice hecha con Antonio Pérez de Montalto ${ }^{10}$. En este caso pensamos que el artífice hubo de ser Antonio Pérez y que Vicente de Salinas actuó como contraste pesando la pieza pues consta el peso de la misma.

El examen tipológico, estilístico e iconográfico de la obra confirma nuestro argumento de que la obra es toledana y de la segunda mitad del siglo XVII. Por otro lado, tanto la calidad de la pieza como su pureza estructural obligarían a considerarla como obra procedente de obrador cortesano o de Toledo.

Aunque el lenguaje artístico durante el siglo XVII se muestra en el área toledana perceptiblemente variable, sin embargo, es claro que podemos definir una serie de pautas tipológicas que definen un centro productor de primera categoría y una platería peculiar y original.

7 Conde de Cedillo: Catálogo monumental y artístico de la catedral de Toledo, Toledo, 1991, p. 153.

8 Archivo Histórico Nacional, Sección Clero, Libro 15.901. En las cuentas del convento de Santa Isabel de Toledo pertenecientes al 30 de mayo de 1660 está registrado un pago a Francisco de Salinas por la limpieza de las lámparas del Santísimo Sacramento.

R. Ramírez de Arellano: Estudio..., p. 358.

10 R. Ramírez de Arellano: Catálogo..., p. 263. 
El tipo se caracteriza tal como vemos en el copón de Salinas por nudo de jarrón, gollete cilíndrico y pie circular de tres zonas. Arranque troncocónico muy pronunciado del vástago con triple anillo de inicio y toro coronando.

Durante la primera mitad de siglo, antes de que quede definida la que sería la creación típica, el inicio del astil aún no es de forma troncocónica y el nudo carece de toro, presentando además un perfil ovoide hasta que haga su aparición la forma de jarrón. Tampoco nos encontramos a finales de siglo ya que en estos últimos años se anuncia lo que sería una transformación hacia un espíritu más barroco; la forma del nudo varía sustituyendo el jarrón por la forma de pera invertida.

La copa suele ser hemiesférica y coronada por tapa. Con bastante regularidad, al igual que ocurre en la obra que estudiamos, las tapas se adornan con pequeñas cupulillas que acercan la pieza al campo arquitectónico.

En cuanto a las notas estilísticas, la pieza fue catalogada como obra estilo Herrera aludiendo a su sobriedad ornamental.

Hay que añadir que en este tiempo predomina en Toledo y en otras platerías peninsulares lo que se ha venido denominando como platería arquitectónica o desornamentada. Si bien coincidimos con el primer apelativo que sin duda halaga a las dos artes, tanto a la platería como a la arquitectura, sin embargo, disentimos del segundo calificativo ya que éste no denota más que un cierto desconocimiento por parte de algunos especialistas.

La desornamentación implica una ausencia absoluta de aquellos elementos que voluntariamente el artista, ya sea escultor, pintor o platero deja fuera de su obra para no permitir que estos contribuyan a envolver la pieza y para evitar infringirle un aspecto que no cuenta entre sus intenciones. Sin embargo, como en el caso que nos ocupa, cuando se logra crear un juego de contrastes de cuerpos y molduras, un sentido colorista que provoca que la pieza vibre lumínicamente mediante la combinación del dorado y los esmaltes, es obvio que nos decantamos por la no utilización de tal terminología.

Es también característica de esta segunda mitad de siglo la sugestiva combinación de los botones ovales en posición vertical-horizontal alternadamente, juego decorativo que contribuye a ensalzar el contraste entre las diferentes partes. Como notas peculiares aparece la decoración de costillas en la subcopa, pie y nudo - detalle que también encontramos en la platería madrileña- y la profusión de contarios que parece ser casi exclusiva de la platería toledana.

Por tanto, es banal hablar de ausencia decorativa cuando espejos, costillas, esmaltes engalanan la obra.

El tipo del copón presenta claros paralelos con otros de la misma época como el del convento de Ajofrín de Toledo, el de la parroquia de Santiago del Arrabal, el del Monasterio de San Clemente de Toledo o el cáliz marcado por Antonio Pérez de Montalto que se guarda en el Museo Nacional de Artes Decorativas, obra muy similar de este mismo año de 1661.

Para concluir es conveniente destacar el papel que nuestro artífice juega en cuanto a la organización corporativa de la cofradía de plateros de San Eloy de Toledo. Sabemos que en el año 1666 era elegido mayordomo junto al platero Antonio Pérez de Montalto y ambos artífices costearon el libro nuevo en el que se englobaban los recibimientos y cabildos, lo que también resulta indicativo de un cierto protagonismo en la vida interna de los plateros. 